\title{
In vitro evaluation of the whitening effect of mouth rinses containing hydrogen peroxide
}

Fábio Garcia Lima ${ }^{(a)}$

Talita Aparecida Rotta ${ }^{(\mathrm{b})}$

Sonara Penso ${ }^{(b)}$

Sônia Saeger Meireles ${ }^{(c)}$

Flávio Fernando Demarco (a)

(a) Department of Restorative Dentistry, School of Dentistry, Federal University of Pelotas, Pelotas, RS, Brazil.

(b) Private practice, Joaçaba, SC, Brazil.

${ }^{(c)}$ Department of Restorative Dentistry, School of Dentistry, Federal University of João Pessoa, João Pessoa, PB, Brazil.
Declaration of Interests: The authors certify that they have no commercial or associative interest that represents a conflict of interest in connection with the manuscript.

Corresponding author:

Fábio Garcia Lima

E-mail: limafg@hotmail.com

Received for publication on Oct 17, 2011 Accepted for publication on Feb 07, 2012
Abstract: The aim of this study was to evaluate the bleaching effect of two mouth rinses containing hydrogen peroxide. Thirty premolars were randomly divided into two groups $(\mathrm{n}=15)$ : Listerine Whitening $(\mathrm{LW})$ and Colgate Plax Whitening (PW). The teeth were fixed on a wax plate and with acrylic resin, at a distance of $5 \mathrm{~mm}$ between each other, exposing the buccal surfaces. All teeth were stored in artificial saliva for 45 days, being removed twice a day to be immersed for $1 \mathrm{~min}$ in each mouthwash, followed by 10 -second washing in tap water. The $\mathrm{pH}$ of each product was measured. Digital images of each tooth were captured under standardized conditions. These images were cut in areas previously demarcated and analyzed in Adobe Photoshop 7.0 using the CIEL*a*b* color space system. Data were statistically analyzed by a paired $t$ test and an independent samples $t$ test $(\mathrm{p}<0.05)$. The $\mathrm{pH}$ values were 5.6 and 3.4 for $\mathrm{LW}$ and $\mathrm{PW}$, respectively. Both treatment groups showed a decrease in the $b^{*}$ parameter $(p<0.01)$, but a decrease of $a^{*}$ was observed only for PW $(\mathrm{p}<0.01)$. While the LW group showed an improvement in lightness $\left(L^{*}\right)(p=0.03)$, the PW group had a decrease in the $L^{*}$ parameter $(p=0.02)$. Within the limitations of this study, it is possible to conclude that both products caused some degree of whitening; however, extreme care should be taken when using Colgate Plax Whitening, since its decline in luminosity might be due to its lower $\mathrm{pH}$.

Descriptors: Hydrogen Peroxide; Mouthwashes; Tooth Bleaching.

\section{Introduction}

Facial and dental aesthetics has been increasingly valued by society in recent years. Since discolored teeth can influence self-esteem and professional relationships, ${ }^{1}$ white and well-aligned teeth represent the most important aspect of the smile.

Various procedures are available to improve tooth color, including whitening toothpastes, professional stain removal, enamel microabrasion, vital and nonvital tooth bleaching, porcelain veneers, crowns, and composite bonding. ${ }^{2}$ However, vital tooth bleaching, when correctly administered, is one of the safest, most effective, and conservative aesthetic procedures available for treating discolored teeth. ${ }^{3}$

Tooth-bleaching agents are based on an oxidation-reduction reaction that releases molecular oxygen, which is capable of penetrating the dental structure, causing a breakdown of the pigments responsible for color alteration. ${ }^{4}$ The three most commonly used methods of vital tooth bleaching in terms of mode of application are in-office, at-home, and over-the-counter (OTC) prod- 
ucts. ${ }^{5,6}$ At-home and dentist-supervised tooth bleaching is based on the use of custom trays with low concentrations of carbamide peroxide (CP) $(10 \%-22 \%)$ or hydrogen peroxide (HP) $(3 \%-8 \%)$ for approximately 2 to $4 \mathrm{~h} /$ day during 2 or 3 weeks. ${ }^{7.8}$ In-office tooth bleaching uses high concentrations of HP $(15 \%-37 \%)$ or CP $(35 \%-$ $37 \%$ ), which may include a light source to increase HP degradation. ${ }^{9} 10$

Clinical trials have shown significant color improvement with both at-home and in-office bleaching protocols. ${ }^{6,8,9,11}$ However, the $10 \% \pm 1 \% \mathrm{CP}$ is still the only product considered safe and effective by the American Dental Association (ADA). ${ }^{12}$ The success of bleaching treatment with $10 \% \mathrm{CP}$ and the increasing number of patients requesting whitening treatment have stimulated the marketing of OTC products for at-home tooth bleaching. ${ }^{5}$ This class of products appeared first in the USA around 2000, as an alternative to treat tooth discoloration at a lower cost than that of traditional professionally prescribed/oriented products..$^{13}$

The various commercial forms of OTC products include gels, rinses, gums, dentifrices, whitening strips, and paint-on films. ${ }^{4,8,14}$ All these products contain low concentrations of $\mathrm{CP}$ or $\mathrm{HP}$, and they can be easily found in pharmacies, supermarkets, and over the Internet. ${ }^{2}$ However, these self-applied bleaching treatments can have harmful effects, and the whitening effects do not seem as effective as those obtained with dentist-oriented treatment. Additionally, there is a lack of clinical trials to provide substantial scientific background regarding these whitening products. ${ }^{5}$

Few independent clinical trials have evaluated the effectiveness of the OTC bleaching products, and most of them have reported the effectiveness and side-effects of the whitening strips. ${ }^{15,16}$ Mouth rinses have become a very popular OTC bleaching product due to the ease of application, low cost, and their widely availability in supermarkets and drugstores. ${ }^{17}$ These products usually contain low concentrations of HP ( $1 \%$ to $2 \%)$, and sodium hexametaphosphate may also be included in the formulation, aiming to protect the teeth surfaces from new stains. Although the sale of bleaching mouthwashes has increased, little information is available about the effectiveness of these products. Thus, the aim of this in vitro study was to evaluate the whitening effect of two commercial mouth rinses indicated as OTC bleaching products.

\section{Methodology}

Sample preparation

The research protocol had the approval of the institutional ethics committee. Thirty sound premolars, recently extracted for orthodontic reasons, were selected for the study. The soft tissues were removed soon after extraction and the teeth were autoclaved. Only teeth darker than A2 (Vitapan Classical Shade Guide, Vita Zahnfabrik, Bad Sackingen, Germany) were selected by a professor of dentistry not directly involved in this study. The roots were sectioned using a water-cooled diamond saw, and the pulp tissues were removed. The pulp chamber was sealed using a dentin bonding agent (Single Bond; 3M-ESPE, St. Paul, USA) and a composite resin (Z250; 3M-ESPE), then the crown-composite resin interface was covered by two layers of nail varnish to prevent stain or whitening from coming through the pulp chamber.

\section{Sample randomization}

The 30 premolar crowns were arranged according to decreasing shade values (Vitapan) and systematically divided into two categories: higher (A2 to A3) and lower (darker than A3) values. Next, the specimens from these two categories were randomized into two groups according to the mouth rinse used $(n=15)$ : Listerine Whitening (LW) and Colgate Plax Whitening (PW). The specimens' randomization was done by the professor cited above and, in order to prevent one group's having darker teeth than the other, the two categories of shades were divided equally among the treatment groups. Basic composition, $\mathrm{pH}$, and manufacturer of each mouth rinse used in this study are shown in Table 1.

\section{Mouth rinse application protocol}

To maintain a standardized distance of $5.0 \mathrm{~mm}$ between each tooth, the specimens were fixed in a wax plaque, and acrylic resin was applied above the wax to fix each tooth rigidly, leaving only the buccal surfaces exposed without considering the area exposed. All the specimens were stored at $37^{\circ} \mathrm{C}$ in artificial saliva prepared by the School of Pharmaceutical Sciences of Ribeirão Preto, University of São Paulo, using a composition previously described,${ }^{18}$ for 45 days and renewed 
Table 1 - Mouth rinses tested.

\begin{tabular}{c|c|c|c}
\hline Mouth Rinse & Composition & $\mathrm{pH}$ Measured & Manufacturer \\
\hline $\begin{array}{c}\text { Listerine } \\
\text { Whitening }\end{array}$ & $\begin{array}{c}\text { Water, alcohol (8\%), hydrogen peroxide } \\
(2 \%) \text {, sodium phosphate, poloxamer 407, } \\
\text { sodium lauryl sulfate, sodium citrate, mint } \\
\text { flavoring, menthol, eucalyptol, sodium } \\
\text { saccharin, and sucralose }\end{array}$ & 5.6 & $\begin{array}{c}\text { KIK Custom Products, } \\
\text { Etobicoke, Canada }\end{array}$ \\
\hline $\begin{array}{c}\text { Colgate Plax } \\
\text { Whitening }\end{array}$ & $\begin{array}{c}\text { Water, sorbitol, ethyl alcohol, hydrogen } \\
\text { peroxide (1.5\%), poloxamer 338, polissorlato } \\
\text { 20, methyl salicylate, menthol, saccharin } \\
\text { sodium, and CI 42090 }\end{array}$ & 3.4 & $\begin{array}{c}\text { Colgate Palmolive } \\
\text { Indústria e Comércio } \\
\text { Ltda., São José dos } \\
\text { Campos, Brazil }\end{array}$ \\
\hline
\end{tabular}

daily. Then the teeth were immersed twice a day in their respective mouth rinse for 1 minute. Before and after immersion, the teeth were washed in tap water for 10 seconds.

\section{Image capture}

Before the experiment, the color of each specimen was registered by a Nikon D80 digital camera (Nikon Corp., Tokyo, Japan) with a $105-\mathrm{mm}$ micro Nikkor (Nikon) lens fixed in an adjustable device at a distance of $5.0 \mathrm{~cm}$ from the tooth. Exposure data were as follows: exposure index, ISO 100; aperture, f/2.8; shutter speed, $1 / 100$ second; focus, manual. The two flashlights (Nikon SB 200) were set at half-power and arranged at 3 and 9 o'clock in relation to the objective and were inclined $45^{\circ}$ to the long axis of the lens, which was positioned perpendicular to the buccal surface of the teeth. The captured images were standardized with respect to time and place, so there was no influence of indirect external light. These imaging systems assured a standardized illumination of the area of interest. In addition, a suitable amount of UV was provided in these designs to mimic the amount of UV in the Commission International de L'Eclairage (CIE) standard illuminant D65. ${ }^{19}$ The same procedure was performed on day 45 of the experiment.

\section{Color change assessment}

The digital images were analyzed before and after the procedure using Adobe Photoshop 7.0 (Adobe Systems Inc., San Jose, USA). The image areas to be analyzed were previously defined as $3 \times 3$-mm quadrilaterals localized in the middle of the crowns, with their vertices marked with a No. 1011 diamond bur (KG Sorensen; Medical Burs Ind. e Com. de Pontas e Brocas Cirúrgicas Ltda., Cotia, Brazil). The CIEL*a*b* color space system was selected through the tool Lab Color system and the values of each color parameter were obtained. The $\mathrm{L}^{*}$ represents the value (lightness or darkness). The $a^{*}$ value is a measure of redness (positive $a^{*}$ ) or greenness (negative $a^{*}$ ), while the $b^{*}$ value is a measure of yellowness (positive $b^{*}$ ) or blueness (negative $\left.b^{*}\right)$. The difference between the color coordinates was calculated according to the following equation: ${ }^{20}$

$$
\Delta \mathrm{E}^{*}=\left[\left(\Delta \mathrm{L}^{*}\right)^{2}+\left(\Delta \mathrm{a}^{*}\right)^{2}+\left(\Delta \mathrm{b}^{*}\right)^{2}\right]^{1 / 2}
$$

Whitening occurs mainly by increasing the lightness (higher $\mathrm{L}^{*}$ ) and reducing the yellowness (lower $\mathrm{b}^{*}$ ) and, to a lesser extent, by a redness reduction (lower $\left.\mathrm{a}^{*}\right)^{4,20}$

\section{Statistical analysis}

Values of $\mathrm{L}^{*} \mathrm{a} \mathrm{b}^{*}$ parameters were evaluated using the paired $t$ test for changes among the same treatment group and by independent samples $t$ test for comparing between the two groups. Differences were considered statistically significant when $\mathrm{p}<0.05$.

\section{Results}

After 45 days of treatment, there were no statistical differences between the LW and PW groups for $\mathrm{a}^{*}$ $(p=0.5)$ or $b^{*}(p=0.6)$. While LW showed an increase in lightness $\left(L^{*}\right)(p=0.03)$, the PW group had a decrease in the $L^{*}$ parameter $(p=0.02)$. These differences were statistically significant between groups $(p=0.01)$. A decrease in redness $\left(a^{*}\right)$ was observed for PW $(p<0.01)$. At the 45-day evaluation, both treatment groups showed a decrease in yellowness $\left(b^{*}\right)(p<0.01)$, as shown in Table 2.

Despite the overall color change $(\Delta \mathrm{E})$, the LW group showed values higher than did PW ( $p=0.01)$, as can be seen in Table 3. 
Table 2 - Means and standard deviations (SD) for $\mathrm{L}^{*}, \mathrm{a}^{*}, \mathrm{~b}^{*}$ and delta values $(95 \%$ confidence interval [CI]) for each tested group at baseline and after 45 days of

\begin{tabular}{|c|c|c|c|c|}
\hline $\begin{array}{c}\text { Color } \\
\text { Parameters }\end{array}$ & $\begin{array}{c}\text { Baseline } \\
\text { Means (SD) }\end{array}$ & $\begin{array}{c}\text { 45-day } \\
\text { Means (SD) }\end{array}$ & $\Delta(95 \% \mathrm{CI})$ & $\mathrm{p}_{\text {(Bas-45-day) }}$ \\
\hline \multicolumn{5}{|c|}{$\mathrm{L}^{*}$} \\
\hline LW & $106.5(9.8)$ & $114.8(13.1)$ & $8.3 \quad(15.5$ to 1.1$)$ & $0.03 \star$ \\
\hline PW & $106.5(9.2)$ & $102.2(11.7)$ & $-4.3(-0.8$ to -7.8$)$ & $0.02 \star$ \\
\hline $\mathrm{p}_{(\mathrm{LW}-\mathrm{PW})}$ & 0.1 & $0.01 \star$ & & \\
\hline \multicolumn{5}{|c|}{$a^{*}$} \\
\hline LW & $134.6(5.9)$ & $133.3(4.5)$ & $-1.3 \quad(0.3$ to -2.9$)$ & 0.1 \\
\hline PW & $136.6(1.5)$ & $134.6(1.8)$ & $-2.0 \quad(0.7$ to -3.3$)$ & $0.006 \star$ \\
\hline $\mathrm{p}_{(\mathrm{LW}-\mathrm{PW})}$ & 0.4 & 0.5 & & \\
\hline \multicolumn{5}{|c|}{$b^{*}$} \\
\hline LW & $132.3(3.9)$ & $131.1(2.7)$ & $-1.2(-0.3$ to -2.1$)$ & $0.01 \star$ \\
\hline PW & $133.3(3.2)$ & $131.8(3.4)$ & $-1.6(-0.9$ to -2.3$)$ & $0.001 \star$ \\
\hline $\mathrm{p}_{(\mathrm{LW}-\mathrm{PW})}$ & 0.4 & 0.6 & & \\
\hline
\end{tabular}

$\star$ Statistically significant difference between groups $(\mathrm{p}<0.05)$.

\section{Discussion}

This study was designated to compare the whitening effect of two available mouth rinses containing low levels of HP. Both products had an acidic pH: 5.6 for LW and 3.4 for PW. The continuous exposure of teeth to acidic products may result in a number of complications such as tooth sensitivity in areas of exposed dentin and incorporation of pigments in the tooth structure with consequent darkening. This might explain what happened to the PW group, which showed a decrease in lightness after 45 days of treatment that was probably due to the superficial enamel demineralization caused by a low $\mathrm{pH}$.

Various methods are used to measure color changes after tooth bleaching, such as shade guides, colorimeters, spectrophotometers, and digital cameras. ${ }^{21,22,8} \mathrm{We}$ did not use a spectrophotometer or a colorimeter for this purpose, which might be considered a limitation in comparing our results with those of other studies. However, the use of digital images, coupled with software in order to obtain CIEL*a*b* color values, is a reliable method that can simplify the methodology and facilitate further comparisons. Furthermore, it is easy to perform, and it needs no expensive equipment. ${ }^{23,13}$

While both treatment groups showed a decrease of yellowness $\left(\Delta b^{*}\right)$, only PW showed a significant reduction in redness $\left(\Delta \mathrm{a}^{*}\right)$. The reduction in the $\mathrm{a}^{*}$ parameter represents, to a minor extent, a color improvement, be-
Table 3 - $\Delta \mathrm{E}$ values (means and $\mathrm{SD}$ ) for both treatment groups.

\begin{tabular}{c|c|c|c}
\hline Treatment Groups & $\begin{array}{c}\Delta \mathrm{E} \\
\text { (Means) }\end{array}$ & $\mathrm{SD}$ & $\mathrm{p}$-value \\
\hline LW & 13.5 & 7.9 & $0.01 \star$ \\
\hline PW & 7.1 & 4.5 & \\
\hline
\end{tabular}

$\star$ Statistically significant difference between groups $(\mathrm{p}<0.05)$.

cause the reduction in $b^{*}$ occurs more rapidly and to a greater extent. ${ }^{24,25}$ Additionally, LW had an increase in lightness $\left(\Delta \mathrm{L}^{*}\right)$ while the PW group had a decrease. This might have occurred because of the different formulations and HP concentration of the mouth rinses, wherein a better effect tends to occur with higher concentration of the agents. ${ }^{15}$ Both groups showed an overall bleaching effect $(\Delta \mathrm{E})$, but the better result for $\mathrm{LW}$ is explained by an improvement in the more expressive parameters, such as $\mathrm{L}^{*}$ and $\mathrm{b}^{*}$, with no decrease in $\mathrm{a}^{*}$. However, PW improved in $a^{*}$ and $b^{*}$, but decreased in $L^{*}$, the most important parameter.

In our study, better results were obtained if the teeth were simply immersed in the mouth rinses - and not rinsed off as suggested by the manufacturer. Thus, improvement in the bleaching effect seems to validate our belief that the method of application of products modifies their efficacy. ${ }^{26}$ Another important fact is that these products are intended as a prerinse, which means tooth- 
brushing after rinse. The mechanical action of brushing might improve the bleaching effect-even though dentifrices have various fillers to facilitate biofilm removal - but they could also promote tooth wear. As we have seen, the products tested in this study have an acidic $\mathrm{pH}$.

We must apply the results of our study with care because of the limitations of in vitro methodologies. Gerlach et al. ${ }^{17}$ in a 1-week in vivo study, did not observe a bleaching effect with a prerinse containing HP. On the other hand, the poor results we found for the PW group in the $\mathrm{L}^{*}$ parameter might not occur in a clinical situation, as Justino et al. ${ }^{27}$ showed: in vitro methodology could promote lower microhardness and higher calcium loss compared with in vivo methodology. Otherwise, although this cited study used deionized water, which does not protect tooth structure from demineralization, artificial saliva has mineral components for this purpose.

The effectiveness and safety of OTC bleaching agents is a serious matter, mainly because their longterm side effects have not been fully studied; in addition, manufacturers conduct their own evaluations or fund researchers to test their products. Thus, there is a need to conduct independent studies using commercially available products to learn the action and possible side effects of mouth rinses and other OTC bleaching products. Using ADA-approved concentrations (10\% $\mathrm{CP}$ ), color improvement longevity of 1 or 2 years has been demonstrated for at-home vital bleaching treatment. ${ }^{8,28}$ However, long-term clinical trials are not available for most such OTC products, like the ones tested in this study. Long-term, randomized clinical trials present the best scientific evidence concerning treatments and, despite the importance of in vitro studies, the true re- sponse of treatments should be determined with independent clinical trials.

\section{Conclusions}

Within the limitations of this study, it was concluded that

1. both mouth rinses tested showed a bleaching effect.

2. Colgate Plax Whitening showed a reduction in lightness.

3. Clinical evaluations must be done to test these products, mainly because only then can we observe the effects of oral habits and the pigments and acidic $\mathrm{pH}$ of the diet on the bleaching result.

\section{References}

1. Dumitrescu AL, Dogaru CB, Dogaru CD. Instability of self-esteem and affective lability as determinants of self-reported oral healthrelated behaviors. J Contemp Dent Pract. 2008 Jan;9(1):38-45.

2. Auschill TM, Hellwig E, Schmidale S, Sculean A, Arweiler NB. Efficacy, side-effects and patients' acceptance of different bleaching techniques (OTC, in-office, at-home). Oper Dent. 2005 MarApr;30(2):156-63.

3. Haywood VB. Treating sensitivity during tooth whitening. Compend Contin Educ Dent. 2005 Sep;26(9 Suppl 3):11-20.

4. Goldberg M, Bohin F, Bonnet E, Claisse-Crinquette A, Dartigues J, Louis JJ et al. Association Dentaire Française (ADF) Medical Devices Commission: Tooth bleaching treatments - A review [Internet]. Paris: ADF; c2007 [cited 2010 Feb 09]. Available from: http:// www.adf.asso.fr/pdf/DossiersADF_EN/TOOTH-BLEACHING. pdf.

5. Demarco FF, Meireles SS, Massoti AS. Over-the-counter whitening agents: a concise review. Braz Oral Res. 2009;23 Spec Iss 1:64-70.

6. Matis BA, Cochran MA, Eckert G. Review of the effectiveness of various tooth whitening systems. Oper Dent 2009 MarApr;34(2):230-5.

7. Joiner A. Review of the effects of peroxide on enamel and dentine properties. J Dent. 2007 Dec;35(12):889-96.

11. Zekonis R, Matis BA, Cochran MA, Al Shetri SE, Eckert GJ, Carlson TJ. Clinical evaluation of in-office and at-home bleaching treatments. Oper Dent. 2003 Mar-Apr;28(2):114-21.

12. American Dental Association. Acceptance Program Guidelines for Dentist dispensed home-use tooth bleaching products [Internet]. 2010 [modified 2010 Feb; cited 2010 Apr 4]. Available from: http:// www.ada.org/ada/seal/adaseal_consumer_shopping.pdf.

13. Donly KJ, Segura A, Henson T, Barker ML, Gerlach RW. Randomized controlled trial of professional at-home tooth whitening in teenagers. Gen Dent. 2007 Nov;55(7):669-74. 
14. European Commission on Consumer Products. Scientific Committee on Consumer Products: Preliminary opinion on hydrogen peroxide in tooth whitening products [Internet]. 0844(4):1-50. [modified 2005 Mar 5; cited 2010 Sep 4]. Available from: http:// ec.europa.eu/health/ph_risk/committees/04_sccp/docs/sccp_ cons_01_en.pdf.

15. Hasson H, Ismail A, Neiva G. Home-based chemically-induced whitening of teeth in adults (review). Cochrane Database Syst Rev. 2006 Oct 18;(4):CD006202.

16. Swift EJ Jr, Heymann HO, Wilder AD Jr, Barker ML, Gerlach RW. Effects of duration of whitening strip treatment on tooth color: a randomized, placebo-controlled clinical trial. J Dent. 2009;37(Suppl 1):51-6.

17. Gerlach RW, Tucker HL, Anastasia MK, Barker ML. Clinical trial comparing 2 hydrogen peroxide tooth whitening systems: strips vs pre-rinse. Compend Contin Educ Dent. 2005 Dec;26(12):874-8.

18. Queiroz GM, Silva LF, Ferreira JT, Gomes JA, Sathler L. Electrochemical behavior and $\mathrm{pH}$ stability of artificial salivas for corrosion tests. Braz Oral Res. 2007 Jul-Sep;21(3) 209-15.

19. Guan YH, Lath DL, Lilley TH, Willmot DR, Marlow I, Brook AH. The measurement of tooth whiteness by image analysis and spectrophotometry: a comparison. J Oral Rehabil. 2005 Jan;32(1):7-15.

20. International Commission on Illumination. Recommendations on uniform colour spaces, colour difference equations and psychometric colour terms. CIE Publication 1978;15 Suppl 2.

21. Wee AG, Lindsey DT, Kuo S, Johnston WM. Color accuracy of commercial digital cameras for use in dentistry. Dent Mat. 2006 Jun;22(6):553-9.

22. Kihn PW. Vital tooth whitening. Dent Clin North Am. 2007 Apr;51(2)319-31.

23. Schropp L. Shade matching assisted by digital photography and computer software. J Prosthodont. 2009 Apr;18(3):235-41.

24. American Dental Association. Acceptance Program Guidelines for Dentist dispensed home-use tooth bleaching products [Internet]. 2006 [modified 2006 Apr; cited 2008 Nov 7]. Available from: http://www.ada.org/ada/seal/standards/guide_home_bleach.pdf.

25. Luo W, Westland S, Brunton P, Ellwood R, Pretty IA, Mohan N. Comparison of the ability of different colour indices to assess changes in tooth whiteness. J Dent. 2007 Feb;35(2):109-16.
26. Zantner C, Derdilopoulou F, Martus P, Kielbassa AM. Randomized clinical trial on the efficacy of 2 over-the-counter whitening systems. Quintessence Int. 2006 Oct;37(9):695-706.

27. Justino LM, Tames DR, Demarco FF. In situ and in vitro effects of bleaching with carbamide peroxide on human enamel. Oper Dent. 2004 Mar-Apr;29(2):219-25.

28. Meireles SS, Santos IS, Bona AD, Demarco FF. A double-blind randomized clinical trial of two carbamide peroxide tooth bleaching agents: 2-year follow-up. J Dent. 2010 Dec;38(12):956-63. 